\title{
Redesign the school yard \\ using Google SketchUp: a pilot project
}

Lia Galani

Lecturer in Teaching Geography and Earth Sciences,National and Kapodistrian University of Athens,

School of Education, Department of Primary Education, Athens, Greece

ligalani@primedu.uoa.gr

\section{ABSTRACT}

The educational project involving the design of a school yard using Google SketchUp, presented in this paper, was originally designed and implemented by undergraduate students at the Department of Primary Education of the National and Kapodistrian University of Athens (UoA) in the context of their studies in the "Teaching Geography with ICT" course. The aim of the project was to create awareness of spaces and their functions, and to redesign those spaces using Google Sketch up according to criteria relating both to the environment and the needs of pupils and their education. The assessment of this initiative, carried out by the undergraduate students during the pilot study showed that there is a distinct need for connecting real spaces with technology and for familiarity with the tools that help pupils visualise the space and that Google SketchUp could be an effective tool that is easily applied to this project and can enrich geography lessons for pupils in upper primary and lower secondary education.

\section{Indexing terms/Keywords}

Spatial design, ICT, Google SketchUp, school geography

\section{Academic Discipline And Sub-Disciplines}

Computer Science; Education; School Geography; Environmental Education

\section{SUBJECT CLASSIFICATION}

ICT in Geography

\section{TYPE (METHOD/APPROACH)}

Practical Study, Integration of ICT

\section{Council for Innovative Research}

Peer Review Research Publishing System

Journal: International Journal of Research in Education methodology

\section{Vol. 7, No.2}

iiremeditor@gmail.com 


\section{INTRODUCTION}

Space is a concept that has occupied the minds of specialists in science, philosophy, education and visual arts for a long time. From the educational point of view, space plays a vital role in social, physical and emotional development of children. Children are invited to observe the variety of spaces that they encounter in their daily lives, to move through them, to understand them and to "build" them.

Education scientists do not only deal with space in its geometric dimension. Pupils' social integration is an outstanding spatial record which thereby is directly linked with space and the way in which they understand and approach it. While space can objectively communicate through its geometric structure, its subjective appreciation by a person or the group of people that experience it, is the parameter that gives the space an identity and an anthropocentric quality.

In terms of social psychology, space is a field of activity that can, through the information it contains, affect skill acquisition, shape behaviour and more generally influence the process of a child growing up. At the same time, it 'imposes' or suggests specific behaviour in its users, linked to its material structure. Simultaneously, though, people are required to interact with the space as part of the social dynamic, and give meaning to it by altering it or reorganizing it.

For young children, the spatial units they identify are connected to their bedroom, their home, their neighbourhood, their school and play spaces (the school yard, squares, urban green spaces etc). However, in spite of the dynamic relationship that links the child with the aforementioned units, and the child-centered educational theories, children's position in the choices affecting that space is still at a primitive level; children's bedrooms are chosen by their parents, the classroom is managed by the teacher, the school and its spaces are managed by the community.

Children experience these spaces as designed for them by adults, but without being consulted and although they spend their school lives accepting the choices made by adults, at the end of their schooling they are expected to become active and responsible citizens.

Hart's theory was based on the above-mentioned problem. [1] [2] According to this theory, in order for young people to become active citizens they must be treated as such. Consequently, they must on the one hand be educated to affect and shape the circumstances in which they live, and on the other, investigate problems in their local environment through cooperative learning. From this starting point and over the last decade, a current has emerged in education that encourages young people's involvement in their environment. [3] [4]

Children's right to participate in decisions that affect their lives is a fundamental human right, enshrined in article 12 of the United Nations' Convention on the Rights of the Child. [5] According to that document, children are capable of forming their own opinions and have the right to freely express their views on anything that affects them. The Convention on the Rights of the Child also states that children should be supported as people with their own rights and ideas. Modern schools require children's input in designing their world. 'Input' means that children are integrated in the process and may express their views and their experiences, giving greater credibility to the decision-making process. In Glasgow, in Merrylee Primary School "pupils ideas have been used to create innovative outdoor, flexible space which aims to foster respect for nature and the environment." [6]

Despite the various decrees and decisions on the matter, children often feel that they are not listened to, or even considered. Therefore, if children are encouraged to participate in design, they are encouraged to participate in decisionmaking processes. This leads to them:

- $\quad$ gradually acquiring a sense of importance as they take part in political processes;

- $\quad$ developing an awareness of the democratic quality of citizens, which teaches them how democracy functions;

- $\quad$ respecting their shared cultural heritage through learning about the history of the spaces they design;

- $\quad$ learning from each other;

- learning to work in a team irrespective of gender or racial differences.

\section{Geography lessons as a vehicle for developing spatial design}

The current Greek school system focuses more on knowledge than on the acquisition of skills associated with spatial design and organisation. Courses like Social Sciences and Geography could be a way to start in that direction. Regarding geography lessons: although current geographical science, from a social perspective, requires ideas that can shape and improve the manmade environment, school geography in Greek schools is mainly knowledge-oriented. It appears, from the division of materials, the syllabus and textbooks [7] [8] that no time or possibility is given to deal with matters relating to pupil's immediate environment. Geography lessons, in upper primary and lower secondary years (the four years being taught), focus on natural and manmade features of Greece, Europe and the World. As a result, teachers of these year groups do not deal with issues relating to pupils' immediate environment, unless they wish to, and then not as part of geography lessons but within activities in Environmental Education.

\section{DESIGNING THE ACTIVITY}

\section{Choice of study region}

Although the school yard environment is deemed to be of particular importance, linked as it is to pupil activity in school 
subjects studied, such as languages, maths, science, geography, art, [9] [10] [11] children's contact with the environment, [12] [13] their experience and investigation of connections between organisms, such as biodiversity and food chains, [9] [10] [14] the development of social skills and interpersonal relationships, [10] [14] in most Greek schools the school yard is amorphous (cement, pebbles, no objects or plants). Literature on the subject, however, shows that 'spatial organisation of school buildings express the educational choices promoted by the educational institution'. [15]

Research also shows that the way in which school yards are designed reveals the way in which adults use them or wish to use them. [16] In their drawings, children represent objects that adults do not include in their specifications. [17] Analysis of sketches shows that children prefer the natural to the built environment [18]: still, school yards are made in cement. Water is an important feature in children's drawings [17]: adult designers do not seem to embrace that view. They view water as a danger, not as a source of entertainment.

The course syllabus of the Greek National Curriculum only addresses classroom-based learning and units of knowledge, even though, it is based on modern educational pedagogical theories. The school yard plays a minor role, and it is barely involved in the learning process. Its role is limited as a space for recreation, for lunch time, for moments when pupils and teachers can relax. The setting of urban schools, in particular, on small plots of land with a particularly dense layout, as well as the extra strain of teaching new classes or specialisms, added to a lack of infrastructure, are some of the usual reasons that discourage even creative teachers from using the school yard environment.

However, in spite of the difficulties in making good use of this space, it remains a place for organised or spontaneous activities. [13] Organised activities that make use of the amorphous school yard environment, leading by teachers, encourages all children to take part. Spontaneous activities are often initiated by pupils themselves and are usually strongly imaginative. A bench, or a corner may be used as hiding places - these become reference points in a traditional school yard. Small groups of children take part in these games and communicate as friends.

According to Germanos, [15] children's perception of the school yard space is structured by distance from the power of teachers: "even in my day, the school yard was divided into sections, defined as: 'official', in which there was a strong presence of the teacher or supervisor, the yard with 'weaker power' and the yard of 'symbolic escape', usually the areas of the yard furthest away in distance (e.g. area near the toilets, school garden, unsupervised areas on the corners of buildings) where pupils find an opportunity to tell each other their secrets, to read, or to communicate in whichever way they wish."

To what extent, though, do school yards express the needs of the people that use it (pupils, teachers)? Do they fulfil their expectations, fit in a modern school, or are they more the expression of past stereotypes? If it were possible to redesign the school yard, what principles should be upheld and what needs should be met? These are some of the questions that pupils had to answer before they redesigned the space using Google SketchUp.

The project to redesign the school yard using SketchUp, presented in this paper, was first tested on 20 undergraduate students (a convenient sample group) before being tried in schools. This test was carried out within the Department of Primary Education of the National and Kapodistrian University of Athens as part of the 'Teaching Geography with ICT' course.

\section{Aims of the Project}

The project "Redesign the school yard using SketchUp" focused on:

- Spatial and functional awareness, redesigning space based on criteria that correspond both to the environment and to the needs of pupils and teachers.

- Skill acquisition in student teachers, including the study of space and spatial design.

- The use and evaluation of SketchUp as a potential tool for use in classrooms to redesign spaces.

The more specific aims of the project were: understanding of geographical concepts relating to scale, drawing to scale, creating a scale map, orientation within space and the use of a compass, the orientation of the map in the space, recording the features of the space, recording and evaluating the views of those who use the space, making decisions based on aesthetic, functional and scientific criteria to reorganise the space, familiarity with new recording and spatial design technologies.

\section{Location of activity - Tools used}

The location chosen for carrying out and observing the project was the school yard at Marasleio School in Kolonaki, Athens. This was judged to be a convenient choice of space as some of the undergraduate students taught lessons or were carrying out their field work at Marasleio, so the space was familiar as well as being easy to access at various times of the day.

The tools used for the recording and design included:

- a questionnaire for pupils and teachers;

- mobile digital devices (mobile phones and tablets equipped with applications chosen for the project: a compass and GPS);

- maps of the area of study from Google Earth;

- drafting paper and tape measures;

- Google SketchUp software. 
Activities involving shaping spaces often involve drawings, objects (miniatures) or modelling materials (plasticine, clay). The choice of using new technologies and computers to redesign spaces and more generally to develop spatial awareness has been flagged up as an effective approach in research by Rafi, Samsudin \& Said [19] and La Ferla et al. [20]

\section{METHODOLOGY}

The methodology used the following five steps. Within the description of these steps we will further discuss and elaborate on the use of the SketchUp software in spatial design, the subject of this paper.

\section{A) Observation and recording of present situation:}

Students walked around the school yard of Marasleio School and mapped it, recording its spaces and what happens in each of them throughout the course of the day. They identified it as a comfortable space over two levels, with a sports hall and a cafeteria that, however, is separated from next door Primary School 15 by temporary barriers along a part of the perimeter. The idea was floated to create a shared schoolyard with Primary School 15, which would work well for both schools as long as break times did not coincide, and on the condition that the sports hall would continue to function and host sporting activities (or any other structured activities) for pupils.

One of the school yards stretches out in front of the sports hall and is completely empty, paved with cement. Along one edge there is a fenced off garden that is not accessible to pupils.

The upper school yard where the cafeteria is located has a small structure that hosts classes from the special school, the cafeteria, an extended roof covering from the cafeteria, an entry to the auditorium and one or two trees. This area is raised up and is separated from the lower yard by steps and fences.

Students then proceeded to measure the yard using various measures, e.g. tape measures, steps, in order to familiarise themselves with different methods of measurement and for them to identify the pros and cons of each method. They sketched the yard to scale and with orientation. They established the position of the yard relative to the buildings around it and looked at the incompatibility of the school yard and a hospital (comment: the yard is separated from a large hospital [Evangelismos] by a road). Later they established the absolute position of the school yard using GPS.

\section{B) Comments based on bibliography data and observation}

Students read articles (indicative sample: Akylas \& Liarakou, [21]; Aggeli \& Manika, [22]; Malone \& Tranter, [13]; Basile \& White, [9]; Dyment, [10]; Woolber \& Tiplady, [14]; etc) and books about school yards, their educational role and their design, then going on to comment on the photographs, their notes, but also the appearance of the school yard itself. They came to the conclusion that it was necessary to redesign the space, making the following comments:

- It provides little in the way of cultural stimulus.

- It imposes limits on children's creativity.

- It is based on an outmoded educational model.

- It diminishes the status of the educational field.

\section{C) Creating a questionnaire for stakeholders (teachers, school students)}

In order to create a questionnaire, students chose to use as a template a questionnaire from the textbook called 'Outdoor school spaces - a tool for education and learning' [23] with adaptations, amendments and fewer questions where necessary.

\section{D) Sorting the responses - recording needs}

Students distributed 12 questionnaires to teachers at the school and 58 to pupils. We note that both teachers and students were kind enough to set out their needs at some length. The majority of students gave single-word responses while their teachers tried to explain their needs.

To analyse the data we used the content analysis method. [24] [25] As a unit of analysis we chose the unit of meaning or the theme.

Responses were read to identify references and, according to their prevalence, they were sorted into thematic categories. Next, content validity was tested, followed by testing the semantic validity of the categories arising from the texts, and necessary changes were made. Coding was checked with a data sample: a second coder studied the data sample and coded it, to check whether there was an agreement in principle about the categories and the way in which they were coded. The level of agreement between the two coders was $89 \%$, which was considered as an endorsement, so the coders proceeded to analyse all the data. The degree of agreement between the two coders increased to $95 \%$. 
The following categories (table 1,2) emerged from the sorted responses, outlining the needs of respondents:

\begin{tabular}{|c|c|c|}
\hline \multicolumn{3}{|c|}{ Table 1: Sorted responses of pupils needs } \\
\hline Pupils' needs & $\begin{array}{l}\text { Number of } \\
\text { responses }\end{array}$ & Percentage \% \\
\hline Basketball court, volleyball court, playground & 58 & 100 \\
\hline Trees, flowers, greenery & 49 & 84.48 \\
\hline Less dangerous floor covering (cement) & 19 & 32.76 \\
\hline More benches and places to sit & 42 & 72.41 \\
\hline Cleaner spaces, more bins in appropriate positions & 21 & 36.21 \\
\hline More water fountains & 14 & 24.14 \\
\hline Shelters & 20 & 34.48 \\
\hline Outdoor classrooms & 12 & 20.69 \\
\hline More colours & 15 & 25.86 \\
\hline Extend surface area of yard & 14 & 24.14 \\
\hline Space to sit and chat & 3 & 5.17 \\
\hline Renovation & 6 & 10.34 \\
\hline Table 2: Sorted responses o & teachers' need & \\
\hline Teachers' needs & $\begin{array}{l}\text { Number of } \\
\text { responses }\end{array}$ & Percentage \% \\
\hline $\begin{array}{l}\text { Spaces for organised play and educational } \\
\text { vities (physical and environmental education etc) }\end{array}$ & 9 & 75.00 \\
\hline More green & 5 & 41.67 \\
\hline Lawn & 2 & 16.67 \\
\hline More benches and seating & 2 & 16.67 \\
\hline Cared for, clean spaces, recycling & 3 & 25.00 \\
\hline Attractive, spacious yard & 4 & 33.33 \\
\hline 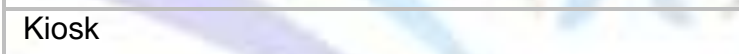 & 4 & 33.33 \\
\hline Repair existing basketball and volleyball courts & 1 & 8.33 \\
\hline Removal of dangerous objects and materials & 1 & 8.33 \\
\hline Sandpit & $2=$ & 8.33 \\
\hline $\begin{array}{l}\text { Performance area, outdoor theatre, space for } \\
\text { eriments and gymnastics }\end{array}$ & 2 & 16.67 \\
\hline Renovate entire yard & 1 & 8.33 \\
\hline Extend surface area of yard & 1 & 8.33 \\
\hline
\end{tabular}

As a next step, a list was created to present the points of agreement between teachers and pupils:

\section{Points of agreement}

1. Creating sports areas, playground, sandpit, areas for organised play and creative activities.

2. Replacing the cement flooring with lawn.

3. Installing seating and shelter.

4. Installing bins and recycling facilities, cleanliness.

5. Increased greenery, trees, bushes, flowers. 
6. Creating areas to be used for teaching and other educational activities.

7. Improving the aesthetics of the yard, more colours (on walls, on objects).

8. An organised and spacious yard for rest and entertainment.

The undergraduate students concluded, on the basis of their own observations and the points of agreement between teachers' and pupils' responses to the questionnaire, that the playground did in fact need redesigning, in order to create a space that would:

- contain objects that would take on a dynamic and an identity through children's interaction with them;

- provide children with the impetus to organise creative activities;

- be a space for education and learning, provide opportunities for creative activities.

\section{E) Designing a school yard using Google SketchUp software, in order to meet the needs described by pupils and teachers, but also to fit with modern perspectives on education and space.}

Google SketchUp 8.0.1. [26] a three dimensional open access modelling software, was used to redesign the space. The user-friendly application uses Google Maps to facilitate viewing the models in their geographical context, as well as allowing users to upload their creations to Google Earth. Although other design programmes do exist, such as CAD, this particular software provides easy-to-use tools for designing objects, and differs from computer assisted drawing in that it allows users to measure space and use real dimensions for objects designed. The ease of use, and the fact that it is open access for non-professional users were factors in favour of selecting this tool. We also wanted trainees to evaluate how easy it would be to introduce such a tool into the school environment, as well as finding out its educational pros and cons.

Undergraduate Students had detailed guidelines for using the tool, they worked in pairs, in order to create interaction, and following the guidelines, downloaded the software from http://www.sketchup.com/download/ and installed it on their computers. Having discussed and created the space in theoretical terms, bearing in mind the needs of pupils and teachers, they then proceeded to use Google Maps as a basis for rebuilding structures and objects in line with specifications. They could also use objects that had been created by other users and saved to the software (fig. $1 \& 2$ ).

The project took place in the computer laboratory of the UoA and took a total of 9 hours.

At the end of the project, participants were asked to comment on the user friendliness of the programme, its functionality, its ability to achieve the project goals, its interactivity and the end result. They were also asked to assess whether it could be used in the classroom.

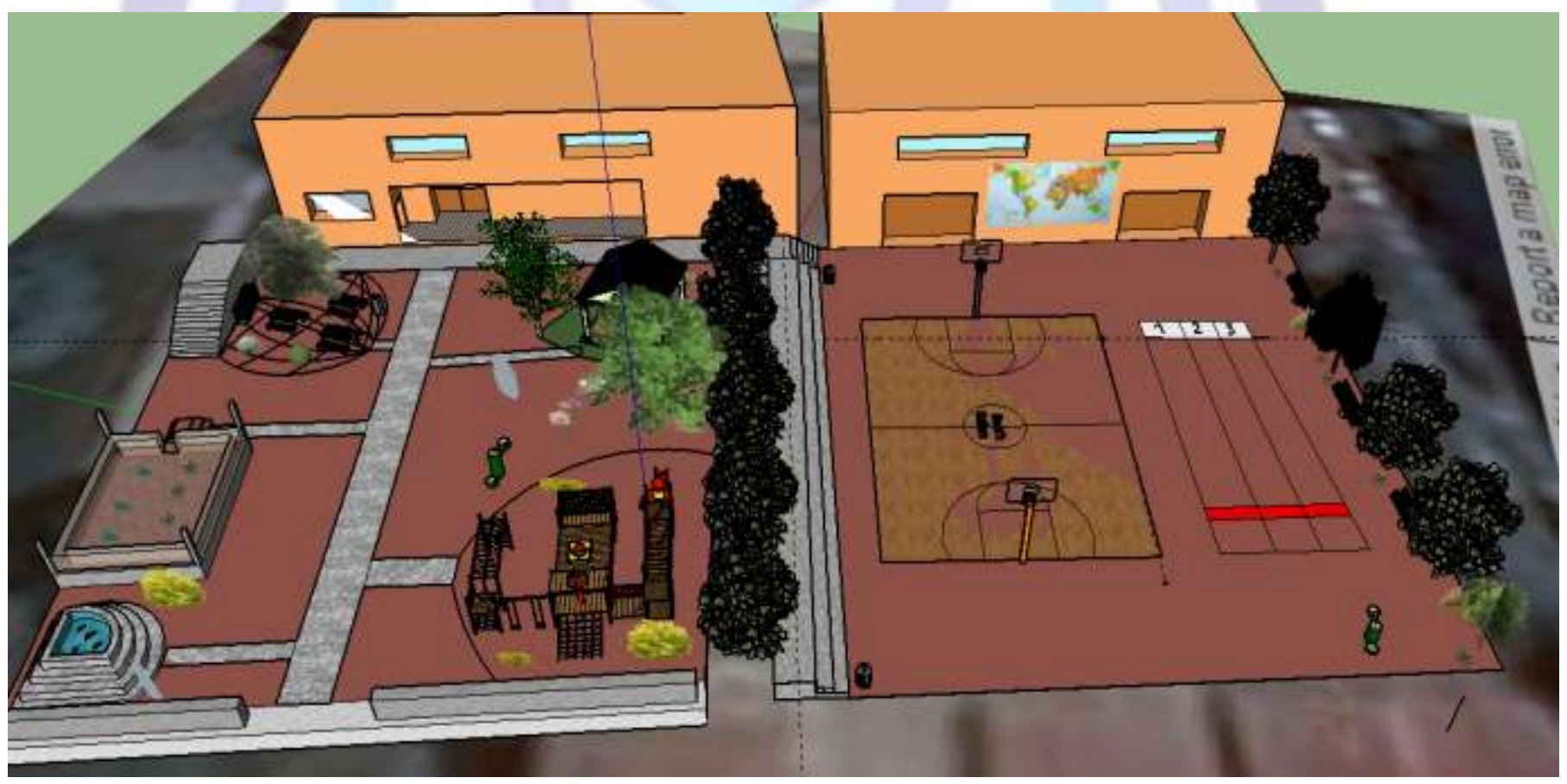

Figure 1:Redesigning the school yard by Panos \& Maria 


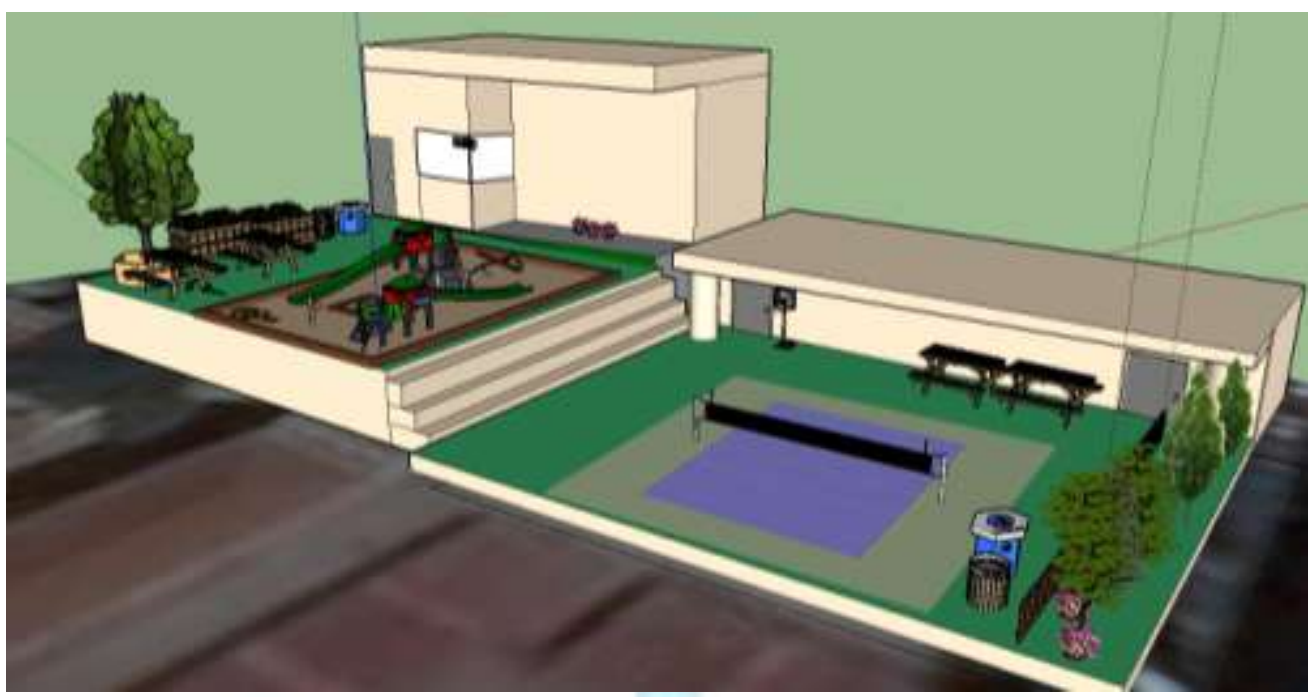

Figure 2:Redesigning the school yard, by Eleni \& Stella

\section{RESULTS}

$85 \%$ of undergraduate students evaluated the software as being user friendly and a simple, functional tool for design.

Maria: "The fact that it was so easy to install, as well as the fact that most of the tools in this version are so simple, make this software ideal for all uses".

Eleni: "In one movement, users can draw lines, shapes or masses, and see their model from different perspectives, while at the bottom of the screen advice and suggestions pop up, helping you to make more of the tools".

Stella: "The simple version of SketchUp doesn't require an advanced operating system, so it runs on most computers with no problem".

$15 \%$ mentioned difficulties linked to the use and adjustment of readymade objects:

Panos: "Probably the biggest difficulty users will encounter is how to place the readymade objects from the $3 D$ Warehouse into the model they're building".

Eleni: "To get a harmonious result, users often need to rotate the objects, or view them from all angles to make sure they were properly positioned. Of course, as you become more familiar with the programme, these difficulties are reduced".

Nikos: "I had problems in placing objects on my plan and adjusting them, e.g. rotating them, changing size." $45 \%$ of students mentioned the guidance provided in an educational video (http://www.sketchup.com/learn/videos):

Katerina: "The educational videos were very helpful, even though they were in English"

Natassa: "When we encountered problems that we hadn't been told about, we consulted the video. Even if you don't understand English very well you understand what to do".

Among the advantages of the tool, students mentioned:

Kostas: "You design spaces based on real-world dimensions and the real-world position of the space as found on Google Earth".

Marios: "The programme offers many possibilities. Its strong point is that it integrates a real map, where you can design or decorate spaces as you wish".

Eleni: "Another positive point is the multitude of choices for objects and colours. It's worth pointing out that within the colours there are even different shades, as well as different materials (such as stone, sand, water etc)".

Regarding the use of the tool in a classroom, 92\% said that the tool could be used in years 5 and 6 of primary education:

Katia: "Personally, if I were to use it, it would be with older pupils (year 5 and particularly year 6), and I would ask them to design something very simple, that wouldn't take a lot of time".

Nikos: "The fact that it is available for free, in combination with all the options it provides users, and how easy it is to navigate, makes this a very important educational tool".

Stella: "I unreservedly believe that this programme could be used in school. However, I would restrict it to children in year 5 and above, who already have some computer knowledge and are more familiar with IT than the younger children". 
Students judged that other aims could be reached through using the software, not only associated with geography lessons. Some suggested it as a tool for teaching geometry $(70 \%)$, while $87 \%$ said that it helps children to develop their creative thinking, as well as encouraging cooperation among pupils. It is worth noting that none of the students raised the issue of IT skills.

Maria: "I think that this software can be used at all levels of education, but for different purposes. Specifically, for younger children it is better for the teacher to handle the software, as support for certain aspects of the lesson. Older pupils, though, can begin to design their own models, with their teachers' help, as part of interdisciplinary projects, such as improving the classroom environment, or their bedroom."

Nikos: "Initially pupils will become familiar with the programme through worksheets that will contain steps for building simple models, later though they will be left to their own devices to build models using critical thought and their own creativity".

Natassa: "Using this tool, students will show great interest in geography lessons, also because they will be able to work in groups with their classmates. The knowledge they acquire through using the programme will be not only theoretical in nature, but also practical. They will also enjoy themselves during the lesson."

Giorgos: "It would be great to use this in a history lesson, to reconstruct a battle (as they imagine it) or to design their own small town, based on the information they have about a population. Of course, both of these projects would require a lot of work."

As for what they got from using the tool, most students' responses focused on the design aspect:

Elena: "I saw space in a different way. I understand that when I discuss things and cooperate with others, I can think more clearly."

Georgia: "It was important for us to design the space. It was challenging, especially as we were designing a school yard. If we were architects, we ought to show the designs to teachers so that they could point out the problems."

Maria: "If children were allowed to design them, our schools would be more beautiful."

Dimitris: "I understood that if I participate in design, I can make the space around me more functional. Thinking about space and doing these activities in geography lessons and other classes make the children more mature citizens."

Loukas: "Design is difficult. How can you satisfy everyone? Often what children like is dangerous, and the teachers don't like it... through the design process I learned to observe what's around me. I saw things that I had overlooked until then."

\section{CONCLUSIONS - DISCUSSION}

Google SketchUp proved to be a useful, functional application over the course of the pilot project. The fact that it is an online tool creates a dynamic context, as users can potentially a) get access to a range of objects created by others, b) ask questions directly to other users, or consult FAQs and get immediate answers, c) work on the programme from their own space, adding unlimited elements to their design. One disadvantage is that it can't be used by schools or individuals that do not have access to the internet, which highlights and intensifies inequalities in education.

The comments of the students participating in the project show the comparative advantages of this tool in research, analysis and spatial design, as demonstrated in the table 3 :

\begin{tabular}{|c|c|}
\hline \multicolumn{2}{|c|}{$\begin{array}{l}\text { Table 3: Geographical Skills provided by the use of } \\
\text { Google SketchUp }\end{array}$} \\
\hline Explore & $\begin{array}{l}\text { Ask questions } \\
\text { Observe } \\
\text { Navigate } \\
\text { Keep notes } \\
\text { Describe } \\
\text { Query } \\
\text { Understand geography concepts } \\
\text { (ie. orientation, geometry of the space, } \\
\text { etc.) }\end{array}$ \\
\hline Analyze & $\begin{array}{l}\text { Spatial concepts } \\
\text { No spatial concepts }\end{array}$ \\
\hline Design & $\begin{array}{l}\text { Units of space } \\
\text { Architectural features }\end{array}$ \\
\hline
\end{tabular}




\begin{tabular}{|l|l|}
\hline & Plans \\
3D maps
\end{tabular}

Therefore, the tool can make a positive contribution to developing spatial awareness (at the level of complex spatial reasoning), although it would seem to address three main areas of spatial awareness:

- In the area of daily life: awareness of the space or "the geography of our vital space", mainly the way in which we perceive the space that surrounds us.

- In the area of nature and the built environment on different scales: awareness of "the space or geography of our natural surroundings".

- In the area of perceptual space: awareness of the space or "geography of our perceptual space", involving relationships and objects that are not necessarily spatial, but can be mapped.

According to the students, the tool can be introduced into the classroom for the final years of primary education. Nevertheless, they point out that in its current state, the programme requires pupils to be very familiar with computers and have a good understanding of English.

The undergraduate students feel that SketchUp is ideal for implementing interdisciplinary activities, linking the scientific concepts students learn in different classes at school. In that case, geography can be linked to history, geometry, art and ICT, providing benefits to pupils and providing them with enough time to investigate the concepts in depth.

Pupils are introduced gradually to the concept of scale and drawing to scale. It is important for them to understand space and the entities that can fit or be created in a particular setting: when pupils reproduce spaces using drawings, modelling or appropriate natural objects, they lose the sense of scale. Using the programme, they can create spaces that, although imaginary, have such a level of detail that they appear real. To-scale drawings of spaces helps spatial designers to recognise which and how many objects can fit within a particular space. They learn to respect the limitations imposed by space and choose which items to introduce based on multiple criteria (aesthetics, needs, functionality, interactive function etc).

SketchUp, as a 3D design tool, introduces GIS to the school context, demonstrating the complexity of space and the need to design it. Attempts to show the factors underpinning space in geography lessons are not always effective. Pupils focus on the information they are more familiar with. Through designing space and interacting with other people, pupils become aware of the variety of links and factors involved in every design process. As a result, they gradually learn to approach the world around them in a multidimensional way.

Designing space using SketchUp seems to encourage dialogue, cooperation and acceptance of diversity (aesthetic or in terms of ability). Pupils immediately see their ideas translated into realistic reproductions, which in turn become the subject of discussion and creative thinking. They understand that shaping their environment, starting with their immediate surroundings, is the indisputable result of study and design and not random acts.

The study of a space highlights its particular characteristics (cultural or natural), and how it can be considered a part of local heritage. Participating in activities relating to shared spaces helps to develop awareness of the everyday tasks and responsibilities of a citizen.

If we wish to move towards an education system whose goal is to create active citizens, then thinking about space and its design should constitute a significant goal of geography lessons. New technologies, and programmes such as SketchUp, can be useful tools. In order for changes of this kind to be made to educational syllabuses, a pilot project should be developed to research the use of similar tools in schools, to respond to specific questions about these tools' effectiveness in lessons.

\section{REFERENCES}

[1] Hart, R. 1995. Children as the makers of a new Geography. In Building Identities: Gender Perspectives on Children and Urban Space, L. Karsten et al., eds. Amsterdam: Institute for Social Geography, University of Amsterdam

[2] Hart, R. 1997. Children's Participation: the Theory and Practice of Involving Young Citizens in Community Development and Environmental care. Earthscan, London

[3] Matthews, H. 2001. Children and Community Regeneration. Creating better Neighbourhoods. London: Save the Children.

[4] Sutton, S. E., \& Kemp, S. P. 2002. "Children as partners in neighborhood place making: Lessons from intergenerational design charrettes." Journal of Environmental Psychology, 22, 171-189

[5] Convention on the Rights of the Child, United Nations 2009 http://www.coe.int/t/dg3/children/participation/CRC-C-GC12.pdf (retrieved 7.5.2013)

[6] [6] Bronwen, C. 2010. Space to develop: How architecture can play a vital role in youngs children's lives, CELE Exchange 2010/6, OECD

[7] [7] Geography Curricula for primary school - http://ebooks.edu.gr/ (in greek) retrieved 5.5.2014 


\section{ISSN 2278-7690}

[8] [8] Geology - Geography books for secondary schools http://ebooks.edu.gr/ (in greek) retrieved 5.5.2014

[9] [9] Basile, C., \& White, C. 2000. "Respecting living things: Environmental literacy for young children." Early Childhood Education Journal, 28(1), 57 - 61.

[10] Dyment, J. 2005. Gaining ground: The power and potential of school ground greening in the Toronto District School Board. Evergreen Foundation: Toronto, CA

[11] Maynard, T. \& Waters, J. 2007. "Learning in the outdoor environment: a missed opportunity?" Early Years: Journal of International Research and Development, 27(3), 255-265

[12] Rivkin, M. 2000. Outdoor experiences for young children. ERIC Digest, ERIC Clearinghouse on Rural Education and Small Schools, Charleston WV

[13] Malone, K. \& Tranter, P.J. 2003. "Children's Environmental Learning and the Use, Design and Management of Schoolgrounds." Children, Youth and Environments 13(2), 87-137.

[14] Woolner, P. \& Tiplady, L. 2009. School gardening as a potential activity for improving science learning in primary schools. Paper presented at BERA 2009, 2-5 Sept. Manchester

[15] Germanos, D. 1998. Space and education processes. Gutenberg - Giorgos and Kostas Dardanos eds (in greek)

[16] Bishop, J. Foulsham, J. 1973. Children's Images of Harwich. Kingston: Kingston Polytechnic Architectural Psychology Research Unit, Environmental Education Research Report No 3

[17] Papageorgiou, N. 2014. Children's Perceptions of open spaces, in general and of a city square's function, in particular. Msc theses, UoA (in Greek)

[18] Rafi, A. Samsudin, K.A. Said, C.S. 2008. "Training in spatial visualization: The effects of training method and gender." Educational Technology \& Society, 11(3), 127-140

[19] La Ferla, V. Olkun, S. Akkurt, Z. Alibeyoglu, M.C. Gonulates, F.O. \& Accascina, G. 2009. An international comparison of the effect of using manipulatives on middle grades students' understanding of three-dimensional buildings. In Bardini, C. Fortin, P. Oldknow, A. \& Vagost, D. eds, Proceedings of the 9th International Conference on Technology in Mathematics Teaching - ICTMT 9), France: University of Metz

[20] Moore, R. 1980. "Collaborating with young people to assess their landscape values." Ekistics 281, 128-135

[21] Akylas, M. \& Liarakou, G. 1999. Green School Yards. A pilot study: Environmental education for primary school. Athens (in greek)

[22] Aggeli, F. \& Manika, M. 2012. School Yards: an innovative participatory experiment https://www.arch.ntua.gr/project/3008, in greek (retrieved 4.3.2015)

[23] Outdoor school spaces - a tool for education and learning. EPEAEK 19982000 (in Greek)

[24] Berelson, B. 1984. Content Analysis in communication research. Nueva York: Hafner.

[25] Weber, R. P. 1990. Basic content Analysis. Series: Quantitative Applications in the Social Sciences. SAGE University Paper

[26] www.sketchUp.com retrieved 5.5.2014

\section{Author' biography}

Dr Lia (Apostolia) Galani (http://www.primedu.uoa.gr/english/human-resources/academic-staff/apostolia-lia-galani.html) is Lecturer of Teaching Geography and Earth Sciences in the Department of Primary Education of the National and Kapodistrian University of Athens, Greece. 